\title{
Aspirin suppresses colorectal cancer initiation in populations without cardiovascular disease by inhibiting cell glycolysis
}

\author{
Chao Yuan ${ }^{1}$ and Yinfang $\mathrm{Wu}^{2 *}$ \\ ${ }^{1}$ Department of Neurology, The Second Affiliated Hospital of Jiaxing University, PR China \\ ${ }^{2}$ The Second Clinical Medical College, Zhejiang Chinese Medical University, PR China
}

\section{Dear Editor}

The previous study has indicated the chemo-protective effect of low-dose aspirin in reducing the incidence of colorectal cancer (CRC) in individuals without cardiovascular disease [1]. However, it is unknown if inhibition of glycolysis in cancer cells by aspirin plays a potential role in this protective effect. Here, we speculate that prophylactic administration of low-dose aspirin decreases the incidence of colorectal cancer upon inhibition of cell glycolysis.

Warburg effect has been consistently observed in and is vital for most types of colorectal cancer, which means cancer cells produce energy by predominant use of glycolysis, irrespective of oxygen availability [2]. Aspirin is a commonly used medication to prevent cardiovascular disease, which has been identified as an inhibitor of glycolysis. Dervisevik et al. [3] reported that aspirin impaired glycolysis in diabetic rat heart as a result of decreased phosphofructokinase (PFK) activity. In addition, aspirin was suggested to attenuate glycolysis in HCT116 colon cancer cells by acetylation of glycolytic pathway enzymes [4]. What's more, aspirin was shown to suppress cancer initiation and progression via promoting cell glycolysis inhibition [5]. All these results undoubtedly have shown that aspirin may have great protective effect against CRC.

In conclusion, aspirin may inhibit cell glycolysis to decrease the incidence of CRC. If so, prophylactic administration of low-dose aspirin presents an ideal strategy for CRC prevention.

\section{References}

1. Cea Soriano L, Soriano-Gabarró M, García Rodríguez LA (2017) Incidence of colorectal cancer in new users and non-users of low-dose aspirin without existing cardiovascular disease: A cohort study using The Health Improvement Network. Int $J$ Cardiol 248: 376-381. [Crossref]

2. Yeluri S, Madhok B, Prasad KR, Perry SL, Thorpe H, et al. (2010) The mediators of warburg's effect in colorectal cancer: targets for future therapy. Br J Surg 97: 32.

3. Dervisevik M, Dinevska-Kovkarovska S, Dimitrovska M, Cipanovska N, Miova B (2014) High dose of aspirin moderates diabetes-induced changes of heart glycogen glucose metabolism in rats. J Physiol Sci 64: 411-420. [Crossref]

4. Marimuthu S1, Chivukula RS, Alfonso LF, Moridani M, Hagen FK, et al. (2011) Aspirin acetylates multiple cellular proteins in HCT-116 colon cancer cells: Identification of novel targets, Int J Oncol 39: 1273-1283. [Crossref]

5. Jiang MJ, Dai JJ, Gu DN, Huang Q, Tian L (2016) Aspirin in pancreatic cancer: chemopreventive effects and therapeutic potentials. Biochim Biophys Acta 1866: 163 176. [rossref]
Copyright: (C2017 Yuan C. This is an open-access article distributed under the terms of the Creative Commons Attribution License, which permits unrestricted use, distribution, and reproduction in any medium, provided the original author and source are credited.
Correspondence to: Yinfang $\mathrm{Wu}$, Department of Hepatobiliary and Pancreatic Surgery, Zhejiang Provincial People's Hospital, No. 158 Shangtang Road, Hangzhou 310014, Zhejiang Province, PR China, Tel: 0086-571-85893311, Fax: 0086-571-85131448, E-mail: binhailantian@gmail.com / sunxiaodong@hmc.edu.cn

Key words: aspirin, colorectal cancer, glycolysis

Received: November 10, 2017; Accepted: November 29, 2017; Published: December 04, 2017 